\title{
Bombeiros: \\ Um Olhar Sobre a Qualidade de Vida no Trabalho
}

Firefighters:

A Look over the quality of life at work

Janine Kieling Monteiro, Daiane Maus,

Fabiane Rosa Machado, Clarissa Pesenti,

Daniela Bottega \& Letícia Bassôa Carniel

Universidade do Vale do Rio dos Sinos
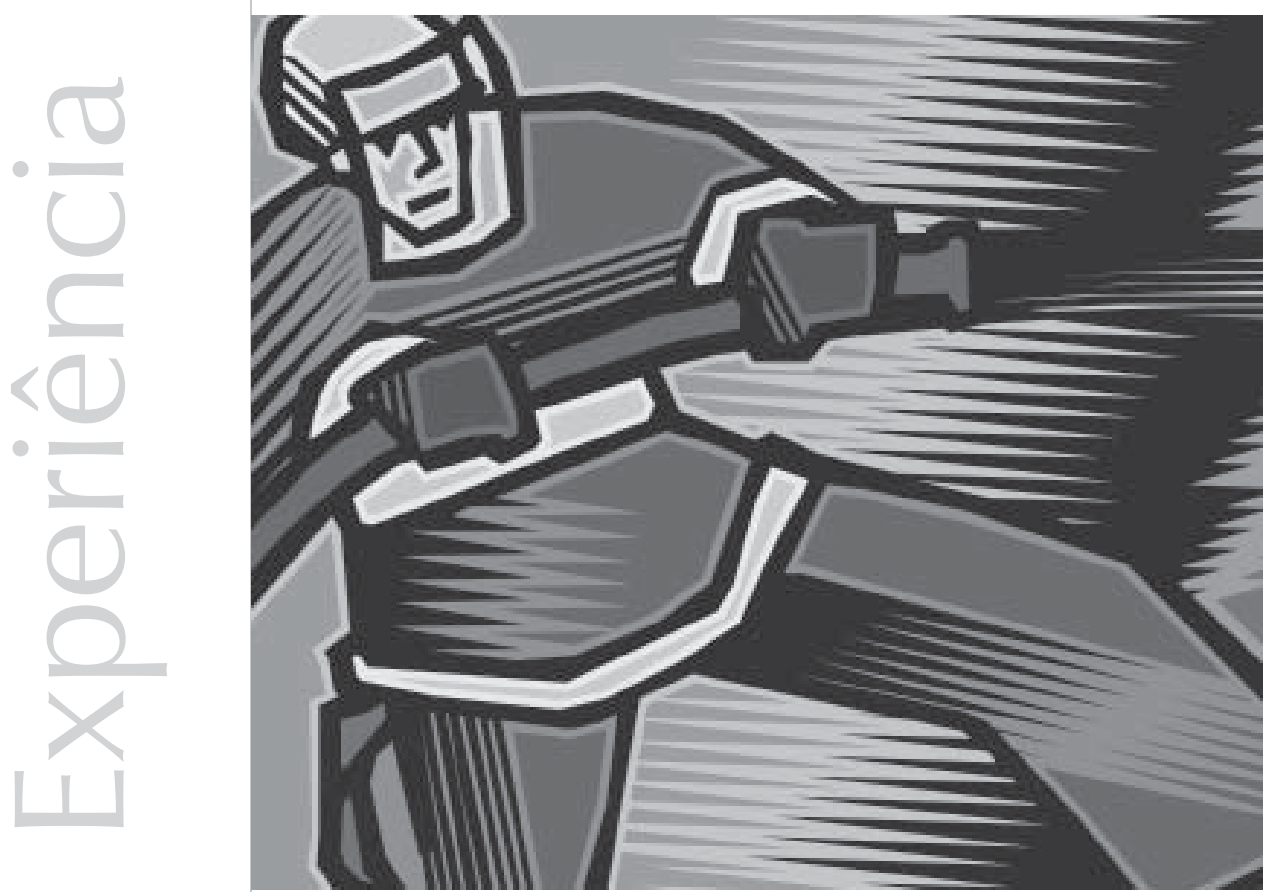
Resumo:Este trabalho apresenta uma intervenção no corpo de bombeiros (São Leopoldo - RS) realizada pelo NEPT (Núcleo de Excelência em Psicologia do Trabalho). Utilizamos um diagnóstico com sessenta e três entrevistas semi-estruturadas sobre o trabalho e funcionamento da corporação. Partindo da análise deste, propusemos palestras sobre estresse e qualidade de vida no trabalho (QVT). Foram levantados questionamentos acerca do mito do herói e do amor pela profissão bombeiro, que deixa em segundo plano seus problemas. Destacou-se o estresse no trabalho por situações traumáticas, como risco de vida eminente e mortes nos salvamentos. Entendemos que as intervenções contribuíram como espaço de escuta que propiciou reflexões a respeito da QVT.

Palavras-chave: qualidade de vida no trabalho, estresse, bombeiros.

\begin{abstract}
This paper presents an intervention at the firefighters' corporation (São Leopoldo - Rs) performed by the NEPT (Núcleo de Excelência em Psicologia do Trabalho). We used a diagnosis made by 63 semi-structured interviews about the corporation's function and operation. From this analysis, we proposed lectures on stress and quality of life at work (QVT). Questions were raised about the myth of the hero and the love for the firefighter profession, that makes people put their jobs at the first place in their lives. The stress caused by traumatic situations, such as constant life risk and deaths in rescues were emphasized. We concluded that the interventions contributed as a hearing opportunity that led to reflections about QVT.
\end{abstract}

Key words: quality of life at work, stress, firefighters.

O trabalho foi realizado na cidade de São Leopoldo - RS, através de uma parceria entre o NEPT (Núcleo de Excelência em Psicologia do Trabalho), vinculado à Unisinos, com o corpo de bombeiros do Município. A demanda foi apresentada pela Diretoria de Ação Social e Filantropia da Universidade, que trazia o pedido do corpo de bombeiros de se realizar um trabalho de prevenção e promoção de saúde na organização. Outros segmentos participaram do projeto, ficando a nosso encargo as questões relacionadas ao levantamento inicial de dados e algumas propostas de intervenção na qualidade de vida no trabalho. Pretendemos, neste artigo, refletir sobre a qualidade de vida no trabalho do profissional bombeiro e sobre o que os profissionais da área de saúde, principalmente os psicólogos, podem fazer para buscar a promoção dessa qualidade.

\section{Qualidade de vida no trabalho}

Em termos históricos, a expressão qualidade de vida no trabalho (QVT) surgiu em meados de 1950, na Inglaterra, em estudos de Eric Trist e colaboradores, baseados no trinômio indivíduo, trabalho e organização. A partir disso, apareceu a abordagem sociotécnica da organização do trabalho, tendo como base a satisfação do trabalhador no e com o trabalho (Goulart e Sampaio, 1999).

Atualmente, a QVT vem ganhando uma preocupação crescente e fundamentada, uma vez que as organizações estão buscando, cada vez mais, o bem-estar de seus colaboradores para se tornarem mais competitivas e alcançarem o mercado globalizado. A QVT, hoje em dia, pode ser definida como uma forma de pensamento que envolve pessoas, trabalho e organizações, entendendo-se estas por corporações, exércitos, escolas, hospitais e igrejas, além de empresas.

Assim, a QVT proporciona maior participação por parte dos trabalhadores e cria um ambiente de integração com superiores, com colegas e com o próprio ambiente de trabalho, visando sempre à compreensão das necessidades dos funcionários (Moretti; Treichel, 2003). 
"... a qualidade é, antes de tudo, uma questão de atitude".

Fernandes
A QVT está relacionada a preocupações com o estresse e à forma de evitá-lo, à busca de satisfação no trabalho, à importância da saúde mental e à necessidade de garanti-la no ambiente de trabalho. Ela visa a buscar possibilidades concretas de, no trabalho, as pessoas serem compreendidas como sujeitos integrais e terem preenchidas as suas expectativas, necessidades, desejos, prazeres, etc (Goulart; Sampaio, 1999).

Outra definição propõe que a QVT seja a adequação entre o que o indivíduo aspira e o que ele efetivamente obtém na vida que leva. Portanto, é uma dimensão subjetiva, e sua avaliação é de extrema importância para medir o estresse, que abrange as diversas áreas da vida: profissional, familiar, lazer, etc... (Cañete, 2004).

Albuquerque e França (1998, citados por Cañete, 2004), afirmam que a QVT pode ser entendida como o conjunto de ações de uma empresa que envolve diagnóstico e implementação de melhorias e inovações dentro e fora do ambiente de trabalho, que visem a proporcionar melhores condições plenas de desenvolvimento humano para e durante a realização do trabalho.

Um programa adequado de QVT busca uma organização mais humanizada, envolvendo, no trabalho, simultaneamente, relativo grau de responsabilidade e autonomia e o recebimento de recursos de "feedback" sobre desempenho, com tarefas adequadas, variedade, enriquecimento do trabalho e ênfase no desenvolvimento pessoal do indivíduo (Walton, 1973, citado por Fernandes, 1996).

Segundo Fernandes (1996), a qualidade é, antes de tudo, uma questão de atitude. Quem faz e garante a qualidade são as pessoas, muito mais do que o sistema, as ferramentas e os métodos de trabalho. Assim, um programa de QVT deve atingir todos os níveis, direcionando esforços para a canalização da energia disponível para o comprometimento humano.

\section{Metodologia}

Foi realizado, inicialmente, um diagnóstico, que teve a finalidade de obter dados a respeito da relação entre saúde mental e trabalho e da corporação como um todo.

Segundo Block (1991), o objetivo do diagnóstico é mobilizar para a ação frente a um determinado problema, uma ação que melhore o funcionamento da organização, sendo que a coleta de dados para este pode se dar de várias formas, entre estas: entrevista, questionários, participação de reuniões, observação direta e a própria experiência em si.

Como procedimento, iniciamos fazendo algumas reuniões com o comando do corpo de bombeiros, e após, fizemos uma apresentação da nossa equipe e da proposta de trabalho para toda a corporação, ocasião em que explicamos como o mesmo se daria, e realizamos o contrato inicial.

Utilizamos, no trabalho, a metodologia proposta pela psicodinâmica do trabalho, que é embasada na idéia de que "os fatos devem ser extraídos da discussão, eles devem ser construídos" (Dejours; Abdoucheli; Jayet, 1994). Com isso, dá preferência às entrevistas com os trabalhadores ao invés de outras possibilidades, numa proposta de reconstrução dos fatos, utilizando os princípios da psicanálise para a escuta clínica adaptados ao contexto de trabalho.

Foram feitas sessenta e três entrevistas individuais semi-estruturadas sobre questões relativas ao trabalho e funcionamento da 
corporação como um todo. Assim, foi entrevistado todo o quadro efetivo dos bombeiros, com exceção dos que estavam de férias ou em desvio de função, sendo sessenta e um homens e duas mulheres. No início das entrevistas, foram explicados os motivos do trabalho, a participação voluntária, bem como o sigilo e a não identificação dos participantes. Os dados obtidos nessas entrevistas foram trabalhados com base no método de análise de conteúdo, de Bardin (1995), que consiste na descrição analítica do conteúdo manifesto e sua posterior interpretação, compreendendo três fases: a pré-análise, a exploração do material e o tratamento dos resultados.

Após essa fase inicial diagnóstica, na qual, em muitos casos, já ocorreu uma intervenção, pois, no momento de escuta dos sujeitos, já se produziu algo terapêutico, chegamos à proposta de trabalho, levando em consideração todas as entrevistas feitas, as sugestões dadas pelos próprios bombeiros bem como a análise dos resultados. Como possibilidades de intervenções, foram propostos um ciclo de palestras, que englobaram questões sobre estresse ocupacional e qualidade de vida no trabalho, além de um grupo de reflexão, que ficaram, ambos, a cargo do serviço de Psicologia do NEPT (Núcleo de Excelência em Psicologia do Trabalho). Criou-se, também, a possibilidade de os interessados realizarem: avaliação nutricional (peso, altura e dobras cutâneas), avaliação de enfermagem (avaliação de saúde) e atendimento psicológico, que foram oferecidos e desenvolvidos por outro órgão dentro da mesma Universidade.

\section{Resultados}

Foram destacadas, nas entrevistas, as seguintes categorias:

O que é ser bombeiro?
Nesse âmbito, os entrevistados mencionaram que ser bombeiro é ajudar a resolver problemas, "fazendo o bem, sem olhar a quem", e lidar com o alto grau de expectativa da comunidade, tendo que ser um herói.

Valorização / imagem

Com relação ao reconhecimento, alguns relatam que se consideram reconhecidos pelo trabalho que fazem, enquanto outros observam que esse reconhecimento, quando existe, é destinado ao comando.

No que diz respeito à valorização do bombeiro perante a comunidade, muitos mencionaram que existe uma alta aprovação da mesma em relação aos serviços que prestam, entretanto ressaltam que, muitas vezes, são responsabilizados por questões que estão fora do seu alcance, como trânsito, falta de materiais, etc...

Já quanto à valorização interna, foi destacado o declínio da remuneração ao longo dos anos, acompanhado da questão das promoções por antigüidade e da falta de critérios para estas. Tudo isso, muitas vezes, obriga-os a buscar uma remuneração complementar. Outro aspecto relevante apontado por eles foi a falta de momentos de confraternização entre a equipe, em datas festivas e aniversários.

Condições de trabalho

A escala de horários e a estabilidade foram vistas como pontos positivos em relação às condições de trabalho. No entanto, a insuficiência de recursos materiais e humanos, somada à falta de treinamentos técnicos de reciclagem, foram apontados como aspectos negativos por alguns entrevistados. Outro fator destacado foi o desgaste, não só físico como emocional, que o bombeiro enfrenta em seu trabalho. 
Relações de trabalho

No que tange às relações de trabalho, estas foram avaliadas como ponto positivo dentro da corporação, visto que se consideram um grupo unido e com um comando acessível, porém, ressaltam o fato de que as constantes mudanças de comando trazem prejuízos ao grupo.

\section{Sugestões}

Como sugestões, apareceram: ministrar cursos e/ou treinamentos técnicos (primeiros socorros, motorista, etc...), acompanhamento nutricional, psicológico, de enfermagem e de educação física, criar um espaço de troca para falar das questões relativas ao trabalho e realizar seminários para a promoção de saúde.

No que diz respeito às intervenções, podemos destacar os seguintes aspectos:

anteriormente, mas tambémo

quanto pesa

carregar esse título de "bombeiro", e muito mais o de "militar", que, aos olhos da sociedade (e deles próprios], é aquele que é forte, que não deve se queixar de nada, que deve suportar tudo.

próprio grupo a partir de uma experiência compartilhada de aprendizagens, visando a
Acreditamos, no entanto, que o aspecto mais importante, ressaltado pelos próprios bombeiros, foi a questão do horário disponibilizado pelo comando para a reunião do grupo, tendo em vista que, para a maioria conseguir participar, teria que vir em horários contrários ao trabalho, sendo que muitos fazem "bicos" fora do expediente.

Em nossa primeira palestra, apresentada sob o título: Refletindo sobre qualidade de vida no trabalho, que contou com um grupo de mais ou menos quarenta bombeiros, houve uma ampla participação destes na discussão; muitos colocaram suas experiências, seu ponto de vista, tornando o encontro "quase" um grupo de reflexão.

O grupo presente discutiu a situação do quartel como um todo, bem como a sua visão sobre seu trabalho. Nas falas, foi possível perceber novamente o quanto de amor existe pela profissão, como citado anteriormente, mas também o quanto pesa carregar esse título de "bombeiro", e muito mais o de "militar", que, aos olhos da sociedade (e deles próprios), é aquele que é forte, que não deve se queixar de nada, que deve suportar tudo. Enfim, o bombeiro é chamado para resolver tudo! É chamado para acabar com problemas, então, como pode ele também ter problemas? maior saúde e bem-estar no trabalho. No entanto, a criação desse espaço não foi concretizada, apesar de, inicialmente, haver sete pessoas interessadas. Nessa proposta, parece que houve certa resistência do grupo. Alguns fatores podem ter influenciado nesse acontecimento: por se tratar de uma instituição militar, fortemente atravessada por valores como o servir, a masculinidade, o cumprimento de ordens, em que a idéia de se ter um espaço para falar do que incomodava "pode ser menos confortável".
Foi dito, na falta de uma escuta, que, não raras vezes, ficam inibidos de falar de seus problemas, por não terem momentos adequados para isso ou por receio das "gozações" e comentários dos colegas.

Outro aspecto levantado por eles diz respeito à demanda de trabalho. Com a chegada do verão, aumentam as chamadas de socorro, por causa das queimadas que a seca promove. Assim, o trabalho torna-se estressante. A fala de um bombeiro ressaltou muito bem esse esgotamento: 
"Se eu estou muito cansado, não tem como estar motivado para o trabalho. Se eu não agüentar mais o cansaço e não tiver como parar, não vai ter psicóloga que consiga me ajudar." A necessidade dos "bicos" também entrou em pauta. Isso ajuda a piorar a qualidade de vida no trabalho e a vida, de modo geral.

“Não há como ter qualidade quando não se consegue desligar nunca...quando não se está em um trabalho, se está noutro..."

Um assunto bastante polêmico surgiu em certo momento, com relação ao regime militar, que, historicamente, é visto como um "regime castrador", que impõe muitas regras e deveres ao profissional. Um sargento colocou para o grupo que, segundo dados históricos, na época da escravidão, só quem não tinha direito de defesa por algum crime eram os escravos e os militares, que eram levados ao tronco e sofriam as chibatadas. Assim, muitos resquícios dessa época ainda restaram, tornando a carreira militar, muitas vezes, um fardo pesado de ser carregado.

Uma comparação foi feita na palestra, nesse sentido, quando um bombeiro destacou que, em empresas privadas, o empregado é chamado "colaborador", alguém que, de alguma forma, está envolvido com o negócio de uma perspectiva que não só a de produzir. No regime militar, o empregado é chamado "servidor", alguém que, como já diz o termo, está implicado em sempre servir.

Na segunda palestra, o tema abordado foi o estresse e o trabalho. Nesta, havia menos bombeiros, em torno de vinte e cinco, desta vez. No início, destacamos que, para reduzir o estresse ocupacional, é necessário, primeiramente, identificar quais são as fontes geradoras desse estresse, e, a partir disso, desenvolver um plano de ação para reduzi-lo
(Green, 1990, segundo Mendes; Borges; Ferreira, 2002). Nessa ocasião, a reflexão girou em torno do quanto o profissional bombeiro está exposto diariamente, e talvez mais que outras categorias profissionais, aos agentes estressores do trabalho.

Ressaltamos ainda a importância de uma boa alimentação, atividades físicas e do equilíbrio emocional para o combate ao estresse, segundo Lipp (1999). Nesse aspecto, foi levantada, por vários bombeiros, a falta da atividade física, que antigamente era permitida no quartel, no horário de trabalho, no tempo em que ficam aguardando chamados, mas essa prática foi proibida porque, aos olhos da sociedade, o bombeiro deve estar em forma, esperando o chamado, e não em uma atividade diferente. Segundo eles, muitas foram as críticas da sociedade ao comando na época, dizendo que os bombeiros não trabalhavam, não faziam nada, só "brincavam" de jogar bola.

Esse é um pensamento comum na comunidade, e, por isso, evitam estar em frente ao prédio do quartel, pois a realização de qualquer atividade diferente, aos olhos da sociedade, passa a impressão de já estarem descumprindo o seu papel de aguardar o chamado por socorro. Para eles, essa posição da sociedade é difícil, pois a atividade física os deixaria mais aptos ao trabalho, mais relaxados para executar suas atividades, e não impediria nenhum salvamento. Mas, mais uma vez, são as regras e a imagem do militar falando mais alto na sociedade.

Um sargento se manifestou nesse sentido, dizendo:

"A sociedade precisa saber que, atrás do bombeiro, tem um ser humano!"
"Não há como ter qualidade quando não se consegue desligar nunca...quando não se está em um trabalho, se está noutro..." 
"... Faço de tudo para conseguir ajudar aquela pessoaque, naquele

momento, precisa de mim. Mas às vezes tudo aquilo que eu faço é pouco, e ela não resiste e acaba falecendo. $\dot{E}$ muito triste saber que, por mais que eu tenha feito tudo o que era possível, ela não resistiu."
Durante essa palestra, por duas vezes, um grupo que estava na guarnição e foi assistir à palestra teve que sair para atender a chamados. Quando os caminhões, que já estavam estacionados ao lado da escola onde realizávamos a palestra, soaram as sirenes, foi inevitável sentir a angústia e o mal-estar que a incerteza sobre o que poderia estar acontecendo nos gerou. Pudemos, logo após o acontecido, falar sobre o que esses picos de adrenalina constantes podem causar no organismo, o que essa tensão emocional pode gerar, e a importância de um ponto de "escape" para tudo isso. Abordamos, aqui, o uso de álcool, drogas e medicação, que é altamente encontrado em pesquisas com bombeiros do mundo todo.

\section{Discussão}

A dor e a alegria de "ser bombeiro"

No imaginário social, a palavra "bombeiro", na maioria das vezes, aparece carregada de um sentido de heroísmo e salvação. De fato, ao ser tarefa de um bombeiro todo e qualquer tipo de salvamento - entre eles o combate e resgate de vítimas em incêndios, primeiros socorros e resgate em situação de acidentes de trânsito, buscas e salvamentos terrestres e aquáticos, ajuda em situações de calamidades como destelhamentos e desabamentos, salvamento em altura, captura de animais, corte de árvores, vistorias contra incêndios, palestras preventivas, e até mesmo partos de emergência a caminho do hospital - fica subjacente ao título um certo brilho de "superherói", um "super-homem" invencível, a solução nas piores tragédias, quando tudo está perdido.

Quem nunca se emocionou ao ver pessoalmente, ou através da mídia, um salvamento envolvendo os bombeiros? O caso é que a outra face da moeda é pouco vista, pouco entendida, pouco trabalhada e até mesmo escondida pelos próprios bombeiros, pela força que carrega o "ser militar". Como relatado por eles:

"Ser bombeiro é servir, servir, sempre servir!" "Ser bombeiro é ter amor à vida dos outros." Essa é uma profissão muito exigida: física, emocional, psicológica e socialmente falando, e, através desse diagnóstico, percebemos o amor e o sofrimento envolvidos no dia a dia desses trabalhadores, o que torna esse trabalho ora uma paixão, ora um verdadeiro esforço pela sobrevivência, como atesta a fala de um bombeiro:

“... Faço de tudo para conseguir ajudar aquela pessoa que, naquele momento, precisa de mim. Mas às vezes tudo aquilo que eu faço é pouco, e ela não resiste e acaba falecendo. É muito triste saber que, por mais que eu tenha feito tudo o que era possível, ela não resistiu."

Nesse aspecto, Dejours (1949/1988) salienta que os trabalhadores podem padecer não só fisicamente em decorrência do trabalho como também apresentar sofrimento mental. Este último é conseqüência da organização do trabalho, que consiste na "divisão do trabalho, no conteúdo da tarefa (na medida em que ele dela deriva), no sistema hierárquico, nas modalidades de comando, nas relações de poder, nas questões de responsabilidade, etc". O sofrimento mental, então, é resultado do enfrentamento entre o sujeito, detentor de uma história personalizada, com a organização do trabalho, que possui uma "injunção despersonalizante." Aliado a isso, segundo Cruz (2005), freqüentemente sobrecarga física e psicológica sinalizam dano que afeta a capacidade de controlar a intensidade do sofrimento, seja esse dano percebido como uma inabilidade para lidar com a frustração no 
trabalho, seja percebido como uma fadiga ou uma lesão.

Normalmente, a carga horária de um bombeiro que atua na "linha de frente do combate" é de 24 horas trabalhadas, com 48 horas de folga. Nessas 24 horas que permanecem na "guarnição", ou seja, no quartel, aguardando algum chamado, a adrenalina é muito alta, pois sabem que, a qualquer momento, o alarme pode soar, e, quando isso se efetiva, saem sem saber ao certo o que vão encontrar pela frente. Nesse momento, muitas coisas podem passar pela sua cabeça, pois só saberão o que os aguarda quando chegarem ao local. As suas falas ilustram bem essa situação:

“... Quando a sirene toca, acabo ficando nervoso. É uma espécie de angústia, eu acho, porque não sei se vou encontrar um incêndio, um atropelamento, um afogamento, ou apenas uma árvore que caiu e está atrapalhando o trânsito. Sem falar na hipótese de ter vítimas... Eu só me acalmo quando chego ao local, se bem que a tensão continua, só que de uma outra forma.."

"Só trabalho quando sei que alguém está em situação difícil, de sofrimento. Por isso prefiro ficar no quartel aguardando, mesmo que parado, porque, se sou chamado, é porque alguém está passando um momento muito complicado".

Sabemos que todo o trabalho é investido de afetividade por parte do indivíduo que o realiza, sendo que esta é a base do psiquismo, elemento essencial na conduta e nas reações individuais. Leontiev (1978, citado por Cruz, 2005) considera que os sentimentos e as emoções são muito importantes, visto estarem presentes no sistema motivacional que, levando à ação e à atividade, irão compor as características próprias que identificam a individualidade.
Assim, o profissional bombeiro lida constantemente com uma forte carga afetiva em seu trabalho. Nas situações que envolvem vítimas, os bombeiros podem, muitas vezes, estar face a face com a morte, ou com cenas muito fortes. É importante ressaltar que, após a ocorrência, eles voltam ao quartel e ao trabalho, sem nenhum suporte que os ajude a enfrentar tais situações, que, por mais cotidianas que sejam para eles, nunca deixam de ser traumáticas. Precisam agir como se nada tivesse acontecido e estarem prontos para novo chamado, como revela o seu depoimento:

“... Quando a vítima é um adulto, eu fico chateado, claro... Mas, com criança, a dor é maior... Às vezes tenho vontade de chorar, mas tenho que ser forte...".

"Não podemos nos envolver com a situação, temos que ter autocontrole. Os colegas mais experientes dão força para os que ficam mais abalados. Não podemos ser emotivos, somos obrigados a ser frios."

"Seria importante um acompanhamento psicológico pós-acidentes, pois, com o tempo, corremos o risco de "ficar meio 18" (gíria do quartel para designar os que ficam "meio loucos").

"É difícil lidar com a morte, também somos humanos."

Nesse sentido, fica evidente a importância de se oferecer um suporte emocional para lidar com essas vivências e situações traumáticas, que tanto poderia acontecer através de um acompanhamento ou atendimento psicológico ou de um grupo de apoio.

A realidade do mundo do trabalho sempre nos impõe com frieza e naturalidade a frase: "deixem suas emoções no portão e entrem
"É difícil lidar com a morte, também somos humanos." 
para trabalhar". A Organização Científica do Trabalho eliminou o afeto das relações de trabalho para que a objetividade predominasse, empobrecendo a atividade mental e expondo o corpo a conversões somáticas e sofrimento psíquico (Dejours et al., 1993/1994).

Encontramos poucos estudos, no Brasil, dedicados a estudar a relação entre saúde e trabalho nesta categoria. Já no âmbito internacional, podemos citar algumas pesquisas relacionadas ao transtorno por estresse pós-traumático (TEPT) e os trabalhadores bombeiros (Koniarek; Dudek, 2001; Regehr; Hill; Glancy, 2000; Corneil et al., 1999; Wagner; Heinrichs; Ehlert, 1998), os quais encontraram maior prevalência de TEPT nesse grupo ocupacional do que na população em geral. Com base nesses estudos, o TEPT pode ser definido como uma condição de debilidade apresentada após a exposição a um evento traumático e estressante.

Conforme Câmara Filho e Sougey (2001), o trauma, na concepção do TEPT, pode ser definido como uma situação experimentada, testemunhada ou confrontada pelo sujeito, na qual houve algum tipo de ameaça à sua vida ou à sua integridade física ou de pessoas a ele afetivamente ligadas. Entre estas, encontram-se situações violentas, como acidentes naturais (enchentes, incêndios, soterramentos, etc.), acidentes automobilísticos, assaltos, estupros, entre outros. Ainda segundo esse autor, tais situações podem afetar a saúde e o rendimento laboral do trabalhador, incluindo a evitação do local de trabalho, os problemas de concentração, as alterações do estado de ânimo, o retraimento social, o abuso de substâncias psicoativas e os problemas familiares.
Outro ponto importante a se considerar é a valorização dessa categoria profissional pela sociedade. Embora esta valorize esses profissionais, muitas vezes os recrimina por um salvamento sem êxito. A demora de algum atendimento sempre é interpretada como falha profissional, e não como uma situação que pode fugir do seu controle, como, por exemplo, o trânsito.

“... Nós, bombeiros, fazemos de tudo para chegar o quanto antes no local chamado. Só que, às vezes, a gente acaba demorando, e não é por nossa culpa... O trânsito nos atrapalha muitas vezes."

Alguns outros aspectos relevantes encontrados nesse diagnóstico também dizem respeito à valorização interna dos profissionais, ao reconhecimento, à satisfação pessoal em ajudar o próximo, ao bom relacionamento entre colegas de trabalho, à estabilidade profissional, etc. Esses fatores positivos aparecem nos seguintes relatos:

“... Eu me sinto valorizado aqui no corpo de bombeiros. Eu sei que o meu trabalho é muito importante para a equipe, para o resultado final."

“... É muito bom quando conseguimos ajudar uma outra pessoa. Sinto-me um herói."

"Com a convivência acabamos nos tornando amigos. Nos ajudamos, de vez em quando, nos problemas pessoais. Como todos passam por situações parecidas, de certa forma, um conforta o outro."

"Mesmo que o salário, a meu ver, seja baixo, tenho uma estabilidade profissional, e isso me deixa tranqüilo."

O famoso "bico" também foi um ponto relevante nas entrevistas. Como a escala é de 
24 horas, nas 48 horas em que estão de folga, a grande maioria dos bombeiros arruma um outro trabalho, informal, para complementar a renda. Como o salário de um bombeiro fica em torno de $\mathrm{R} \$ 1.000,00$, esses "bicos" dão um suporte extra à família. A dificuldade está na sobrecarga de trabalho que isso gera, pois, nas horas destinadas ao descanso, à convivência familiar, ao relaxamento para o próximo dia de trabalho, o bombeiro está em outro trabalho. Assim, não existe o descanso, e, na volta ao quartel, as pressões parecem se tornar ainda maiores.

No que diz respeito à instituição e regime militar, que foi citada como "castradora" e rígida, cabe destacar que o poder não é algo que possui uma natureza, uma realidade a partir da qual seja possível buscar uma essência que traga em si características universais. O poder não é algo unitário, mas sim, heterogêneo, e está em constante transformação. Ele não pode ser definido como um objeto natural, muito pelo contrário, o poder é algo que advém das práticas sociais e é constituído historicamente (Machado, 1979), sendo que o poder nas organizações é exercido a fim de que certos objetivos sejam alcançados, e, nesse contexto, observa-se o caráter intencional do poder (Rabinow; Dreyfus, 1995). As práticas de poder, em uma organização, só poderão ser entendidas como tal a partir do entendimento de como as relações de trabalho se estabelecem nessa instituição. No caso da instituição estudada, fica claro que, ao mesmo tempo em que muitos oficiais do comando procuram evoluir e buscar um relacionamento mais aberto com a corporação como um todo, muitas regras e burocracias do funcionamento institucional permanecem iguais há anos.

De acordo com os pontos apontados acima, fica evidente que o profissional bombeiro está facilmente exposto a situações que propiciam algum tipo de sofrimento, prejudicando, assim, sua qualidade de vida, e, por isso, um auxílio psicológico pode contribuir muito como suporte a fim de que ele possa aprender a criar estratégias para lidar com essas situações.

\section{Considerações finais}

Quanto à proposta das palestras e sua realização, pensamos que esta nos possibilitou criar o espaço de escuta pretendido no grupo, de uma forma natural e com grande número de participantes. Temos que considerar que as atividades ocorreram em horários concomitantes com o trabalho, e que a proposta era de uma palestra. A interação dos participantes e a troca de experiências entre eles podem demonstrar a necessidade de um espaço de escuta, que foi possibilitado através da proposta que gerou menos ansiedade (em relação a um grupo de reflexão) e dentro de um período no turno dos bombeiros participantes. Assim, esses encontros ficaram marcados pela grande participação dos bombeiros presentes e pela nossa satisfação em poder proporcionar uma reflexão que talvez faça eco mais adiante. Para nós, essas palestras podem ter funcionado como o início de um trabalho mais profundo em termos subjetivos, plantando uma semente para um maior envolvimento desses profissionais com a sua saúde mental.

Para finalizar, podemos destacar que o trabalho pode ser fonte de prazer e sofrimento, provocando uma contradição, que é norteada por um movimento de luta do trabalhador pela busca constante do prazer e pela evitação do sofrimento, com a finalidade de manter seu equilíbrio psíquico. Essa dinâmica é responsável pela saúde psíquica, sugerindo que não é a simples existência do prazer ou do sofrimento o indicador de saúde, mas a quantidade de estratégias que podem ser utilizadas pelos 
sujeitos para fazer frente às situações que causam sofrimento e transformá-las em situações geradoras de prazer (Mendes; Borges; Ferreira, 2002). Entendemos que tanto o diagnóstico quanto as palestras contribuíram para a criação de um espaço de escuta que propiciou reflexões acerca das vivências de prazer e sofrimento no trabalho dos bombeiros e, em conseqüência, serviu para pensar em alternativas que visem a buscar maior promoção de QVT e prevenção de doenças.

Concordamos com Cardoso (1999/2003) quando este afirma que a qualidade de vida envolve a satisfação e as expectativas tanto humanas quanto técnicas por parte do trabalhador, e, portanto, melhorá-la não é algo que se resolva em um só trabalho, mas é um processo infindável, que necessita do comprometimento do indivíduo com um estilo de vida.
Cabe mencionar aqui também, novamente, o quanto é importante a Psicologia se fazer presente em espaços como esse, e buscar auxiliar na saúde desse trabalhador, que tem uma função tão importante e valorizada na sociedade, mas que, por outro lado, passa por situações estressantes, inclusive de risco de vida iminente no seu dia a dia, e, por isso, pode estar mais propenso a adoecer.

Como seqüência deste trabalho, iniciamos uma pesquisa para investigar possíveis transtornos ou psicopatologias relacionadas à profissão do bombeiro, entre estes: o transtorno por estresse pós-traumático, a depressão, a ansiedade e o abuso de substâncias psicoativas. Também estamos desenvolvendo oficinas com temas de interesses trazidos pelos bombeiros que participaram do nosso estudo para discutir aspectos relacionados à saúde e à QVT. 


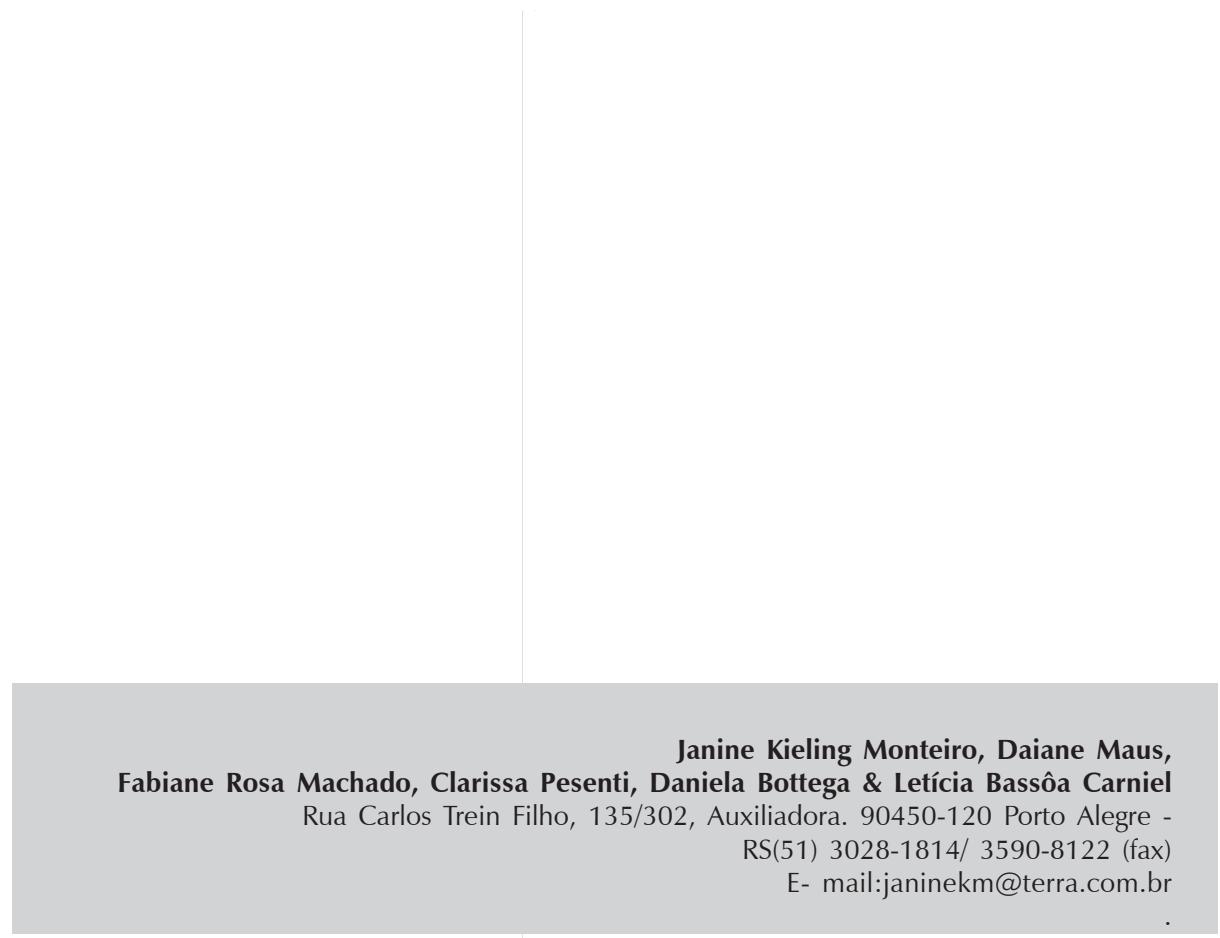

Recebido 18/08/05 Reformulado 21/08/06 Aprovado 24/10/06

BARDIN, L. Análise de Conteúdo. Lisboa: Ed. Edições 70, 1995.

BLOCK, P. Consultoria: o Desafio da Liberdade. São Paulo: Makron, McGraw-Hill, 1991, pp. 178-190.

CÂMARA FILHO, J. W. S.; SOUGEY, E. B. Transtorno de Estresse pósTraumático: Formulações Diagnósticas e Questões sobre Comorbidade. Revista Brasileira de Psiquiatria, São Paulo, v. 23 , no $4,2001$.

CAÑETE, I. Qualidade de Vida no Trabalho: muitas Definições e Inúmeros Significados. In: C. Bitencourt e cols. Gestão Contemporânea de Pessoas. Porto Alegre: Bookman, pp.386-411, 2001.

CARDOSO, W. L. C. D. Qualidade de Vida e Trabalho: uma Articulação Possível. $3^{\text {a }}$ ed. (2003). In: L. A. M. Guimarães e S. Grubits (orgs.) Saúde Mental e Trabalho, vol III, $3^{3}$ ed. São Paulo: Casa do Psicólogo, 1999, 1 ed., pp.71-94.

CORNEIL, W; BEATON, R.; MURPHY, S.; JOHNSON C.; PIKE, K. (1999). Exposure to Traumatic Incidents and Prevalence of Posttraumatic Stress Symptomatology in Urban Firefighters in two Countries. Journal of Occupational Health Psychology, Fairfax, v. 4 no 2, pp.131-41, 1999.

CRUZ, R. M. Saúde, Trabalho e Psicopatologias. In: B. W. Aued (org.). Traços do Trabalho Coletivo. São Paulo: Casa do Psicólogo, 2005, pp.201-235.

DEJOURS, C.; ABDOUCHELI, E ; JAYET, C. Psicodinâmica do Trabalho:Contribuições da Escola Dejouriana à Análise da Relação Prazer, Sofrimento e Trabalho. São Paulo: Atlas, 1994.

DEJOURS, C. (1988). A Loucura do Trabalho: um Estudo da Psicopatologia do Trabalho. 3 ed. São Paulo: Cortez - Oboré, 1 ed.,1949.

FERNANDES, E. Qualidade de Vida no Trabalho - como Medir para Melhorar. Bahia: Casa da Qualidade, 1996.
KONIAREK, J.; DUDEK, B. Post-traumatic Stress Disorder and Fire Fighters' Attitude to their Job. Medycyna Pracy, Warsaw, v. 52, no 3, pp. 177-83, 2001.

GOULART, I.; SAMPAIO, J. (orgs.). Qualidade de Vida, Saúde Mental e Psicologia Social. São Paulo: Casa do Psicólogo, 1999.

LIPP, M. (org.). O Stress Está dentro de Você. São Paulo: Contexto, 1999.

MACHADO, R. Por uma Genealogia do Poder. In: M. Foucault. Microfísica do Poder. Rio de Janeiro: Graal, pp.VII-XXIII.

MENDES, A. M.; BORGES, L. O.; FERREIRA, M. C. (orgs.). Trabalho em Transição, Saúde em Risco. Brasília: Editora da Universidade de Brasília, 2002.

MORETTI, S.; TREICHEL, A. Qualidade de Vida no Trabalho e autoRealização Humana. Revista Leonardo pós-Órgão de Divulgação Científica e Cultural do ICPG, Blumenau, 1,3, pp.73-80, 2003.

RABINOW, P.; DREYFUS, H. Poder e Verdade. In: P. Rabinow \& H. Dreyfus. Michel Foucault: uma Trajetória Filosófica. Rio de Janeiro: Forense Universitária, 1995.

REGEHR, C.; HILL, J.; GLANCY, G. D. Individual Predictors of Traumatic Reactions in Firefighters. The Journal of Nervous and Mental Disease, Baltimore, v. 72, no 9, pp. 693-9, 2000.

WAGNER, D.; HEINRICHS, M.; EHLERT, U. Prevalence of Symptoms of Post-Traumatic Stress Disorder in German Professional Firefighters. The American Journal of Psychiatry, v. 155, no 12, pp.1727-32, 1998. 